\title{
Comparison of prognostic factors in patients in phase I trials of cytotoxic drugs vs new noncytotoxic agents
}

\author{
C Han ${ }^{1,2}$, JP Braybrooke ${ }^{1,2}$, G Deplanque ${ }^{1,3}$, M Taylor', D Mackintosh', K Kaur', K Samouri', TS Ganesan', \\ AL Harris' ${ }^{1}$ and DC Talbot*,I \\ 'Cancer Research UK Medical Oncology Unit, Churchill Hospital, Headington, Oxford OX3 7LJ, UK
}

The aims of this study were to identify prognostic variables for toxicity and survival in patients with cancer participating in phase I clinical trials and compare characteristics of those treated with cytotoxic chemotherapy (CT) and non-cytotoxic drugs (non-CT). Data were collected from 420 (I I4 CT, 306 non-CT) patients enrolled in 16 phase I trials (five CT and II non-CT trials) in one cancer centre. Analyses of all patients were used to compare treatment groups, identify predictive variables for toxicity and to estimate prognostic factors in overall survival (OS). These were used to develop a prognostic index (PI). Multivariate analysis found those patients with better performance status, fewer sites of metastases, baseline $\mathrm{Hb}>12 \mathrm{~g} \mathrm{dl}^{-1}$ and WBC or LDH in the normal range had significantly better OS. Male gender, platelet count $<450 \times 10^{9} \mathrm{I}^{-1}$, high WBC or treatment with a non-CT phase I agent significantly reduced the chance of grade $3 / 4$ toxicity. Overall survival was not significantly different between the CT and non-CT groups ( 260 vs 192 days, $P=0.47$ ) except for those with liver metastases ( 228 vs 137 days, $P=0.02$ ). Overall tumour response was 4.9\% (95\% Cl: 2.7-7.0\%). The Pl identified three distinct patient groups with median survival of 32 I, 257 and I I 7 days. In conclusion, entry into a phase I trial of a non-CT drug is a safe option for heavily pretreated patients with cancer. The PI generated from these data can estimate the survival probability for patients entering phase I studies.

British Journal of Cancer (2003) 89, | |66- | |7|. doi:I0.1038/sj.bjc.660 I2I8 www.bjcancer.com

(C) 2003 Cancer Research UK

Keywords: phase one; cytotoxic; noncytotoxic; prognosis; multivariate analysis

Careful phase I clinical trial design includes avoidance of unacceptable toxicity to participating patients with cancer and minimisation of the number of patients treated with ineffective drug doses. Despite the need for the development of new therapies, and the importance attached to the findings of phase I trials in oncology, surprisingly little information is published about patient selection and potential prognostic indices that may aid the clinician in predicting, and discussing, the likely outcome for an individual. Increasingly, with the development of biological therapies there is a need to evaluate patient outcome in phase I studies with newer agents in comparison to those treated with traditional cytotoxic drugs. This is important for determining whether or not these trials can be considered as an ethical treatment option or whether they compromise survival and quality of life.

Typically, in oncology, phase I trials have been offered to patients with cancer who have a good performance status and have either failed standard treatment or for whom no standard therapy exists. Despite the emphasis on evaluation of side effects, and determination of a maximum tolerated dose (MTD), tumour responses remain an important secondary end point. Reported response rates for phase I trials are generally between 1 and $10 \%$

*Correspondence: DC Talbot; E-mail: denis.talbot@cancer.org.uk

${ }^{2}$ Both authors contributed equally to this work.

${ }^{3} \mathrm{G}$ Deplanque's current address: Département d'Oncologie Médicale, Hôpital Claude Bernard, 57072 Metz, France.

Received 20 November 2002; revised 29 May 2003; accepted 29 June 2003
(Estey et al, 1986; Decoster et al, 1990; Bachelot et al, 2000) with most responses seen at $80-120 \%$ of the recommended phase II dose (Von Hoff and Turner, 1991). Cytotoxic drugs that do not show antitumour activity in phase I trials rarely undergo further evaluation (Von Hoff and Turner, 1991; American Society of Clinical Oncology, 1997; Sekine et al, 2002).

Previous reviews of phase 1 study data have used multivariable analyses to explore factors associated with toxicity and prognosis. Dosage level and age over 65 years are independently associated with grade 3 or 4 toxicity (Bachelot et al, 2000). Poor performance status (WHO grade 2 or 3) (Janisch et al, 1994; Bachelot et al, 2000), elevated lactate dehydrogenase (Bachelot et al, 2000), lower albumin, elevated platelet counts and previous cisplatin therapy (Janisch et al, 1994) have all been identified as independent adverse prognostic variables. Analyses have mostly been limited by small sample sizes and have not compared cytotoxic (CT) with non-cytotoxic (non-CT) drugs. For new non-CT agents such as antiangiogenic drugs or matrix metalloproteinase inhibitors, tumour shrinkage may be less likely and chronic drug administration might be required before side effects become apparent. Careful patient selection is therefore important to maximise the information obtained from these clinical trials.

In this retrospective study, we compared patients from a single centre entered into phase I studies with CT drugs or non-CT drugs. A range of clinical, biochemical and haematological factors were assessed by both univariate and multivariate analysis for toxicity and to provide prognostic indicators that could be used for development of a predictive model for survival in patients entered into phase I studies. 


\section{METHODS}

\section{Patients}

We identified 16 (CT drugs: five; non-CT drugs: 11) phase I clinical trials conducted by the Cancer Research UK Medical Oncology Unit, Oxford, between 1991 and 2000 (Table 1). A total of 420 individual patient records and case report forms were used as the data source. Information collected included demography, performance status, diagnosis, stage, number/sites of metastases, previous therapy, haematological and biochemical indices, start/ end date of study drug treatment, dose level, toxicity grades, date last seen and date of death. Tumour response was assessed by WHO (Miller et al, 1981), or South West Oncology Group (SWOG) criteria (Green and Weiss, 1992) according to the phase I study protocol. Toxicity was assessed by the NCI-CTC criteria (National Cancer Institute: Guidelines, 1988). When required by the individual trial protocol, radiological review was performed by an independent review panel. In other cases, tumour response was reported by an independent consultant radiologist blinded to the treatment intervention. All studies were conducted in accordance with the Declaration of Helsinki and were approved by Cancer Research UK and the local research ethics committee.

\section{Statistical methods}

Contingency tables were analysed using the Pearson's $\chi^{2}$ test. The survival was measured from the first day of treatment on the phase I trial to the time of death or the time of last follow-up. The logrank test was used to perform univariate analysis for survival and the survival curves were estimated by the Kaplan-Meier method. Prognostic factors for survival were evaluated in multivariate analyses by Cox proportional hazards regression. Logistic regression was performed for estimating the predictors of grade $3 / 4$ toxicity in multifactorial analysis. All statistics were performed using the Stata package release 7.0 (Stata Corporation, TX, USA). Based on the five risk factors from the multivariate survival model, we generated a prognostic index as a survival probability estimator $\left(S(t)=\exp \left[-H_{0}(t) \times \exp (\mathrm{PI})\right]\right.$, where $S(t)=$ survival time, $H_{0}=\mathrm{a}$ step function over time, $t=$ time, and $\mathrm{PI}=$ prognostic index. The hazard and estimated survival probability at any time depends only upon the PI.

Table I Phase I trials included in analysis

\begin{tabular}{lcl}
\hline $\begin{array}{l}\text { Investigational agent/ } \\
\text { molecular target }\end{array}$ & $\begin{array}{c}\text { Number of } \\
\text { patients }\end{array}$ & Reference \\
\hline Non-cytotoxic & & \\
$\quad$ Matrix metalloproteinase inhibitor & 9 & In preparation \\
Matrix metalloproteinase inhibitor & 6 & Macaulay et al (1999) \\
Mitochondrial inhibitor & 1 I & Propper et al (1999) \\
Matrix metallo-proteinase inhibitor & 92 & Levitt et al (2001) \\
8-Chloro cyclic AMP & 33 & Propper et al (1999) \\
Antiangiogenesis & 50 & Jones et al (1999) \\
Dendritic cell therapy & 5 & Chao et al (2003) \\
Gene therapy & 23 & Unpublished \\
EGFR inhibitor & 5 & Twelves et al (2002) \\
Protein kinase C partial agonist & 56 & Philip et al (1993) \\
Retinoid & 16 & Jones et al (2003) \\
& & \\
Cytotoxic & & \\
Topoisomerase I/II inhibitor & 12 & Propper et al (2003) \\
Topoisomerase I inhibitor & 35 & Braybrooke et al (2003) \\
Topoisomerase I inhibitor & 21 & Submitted for publication \\
Bio-modulation of 5-FU & 21 & Braybrooke et al (2000) \\
Cyclophosphamide, methotrexate & 25 & O'Byrne et al (1998) \\
and infusional 5-FU & & \\
\hline
\end{tabular}

\section{RESULTS}

\section{Patients}

A total of 420 patients (210 males, 210 females), median age 56 years (range 22-87 years) were included in the analysis. The cancer types reflect referral patterns to the Oxford Medical Oncology Unit, with the majority of patients having colorectal (78), melanoma (65), breast (45), renal (39), ovarian (38) and lung (37) cancers as their primary tumour site. The overall response rate for all patients was $4.9 \%$ (0.3\% complete response, $4.6 \%$ partial response) with $19.2 \%$ patients obtaining disease stabilisation for 3 months or longer.

\section{Comparison of CT and non-CT groups}

In all, 306 patients were treated with non-CT drugs and 114 with CT (Table 2). The median age was slightly lower for patients receiving CT drugs (55 vs 58 years; $P=0.04$, Mann-Whitney $U$ test), although more patients had a performance status of zero in the non-CT trials ( $P=0.02$, Fisher's exact test). Significantly, more women were treated with CT drugs $\left(P<0.001, \chi^{2}\right.$ test $)$ reflecting inclusion of a study of a novel schedule of cyclophosphamide, methotrexate and infusional 5-FU for women with breast cancer (O'Byrne et al, 1998). There was no significant difference in the numbers of sites of metastases between groups $\left(P=0.2, \chi^{2}\right.$ test $)$ but significantly more patients in the CT studies had liver metastases $\left(P<0.001, \chi^{2}\right.$ test). Objective tumour response rates were higher in patients receiving CT therapy $\left(P<0.001, \chi^{2}\right.$ test). The median duration of time on trial was shorter for patients receiving non-CT treatment (51 vs 73 days, $P<0.001$, MannWhitney $U$-test). There was no significant difference in the median overall survival (192 days (range 4-2405), non-CT vs 260 days (range 10-1136), CT; $P=0.47$, Log-rank test) and no difference in the numbers of patients who had died within 3 months of study start (20.6\% non-CT vs $16 \%$ CT). However, in patients with liver metastases $(n=127)$, treatment with CT drugs resulted in a significant survival advantage compared to non-CT drugs (median 228 vs 137 days, $P=0.02$, log-rank test). There was no difference in survival between groups for patients with lung metastases.

\section{Survival analysis}

When all patients were analysed together by univariate analyses, WHO performance status $>1$, white blood count above the normal range, low haemoglobin $\left(<12 \mathrm{~g} \mathrm{dl}^{-1}\right)$, raised platelets $\left(>450 \times 10^{9} 1^{-1}\right)$, lactate dehydrogenase above the normal range, low albumin, number of metastatic sites $>1$, presence of liver and/ or lung metastases and stage of disease were all significant adverse factors for predicting reduced survival (Table 3). Tumour type and treatment with either CT or non-CT drugs were not significant predictors of survival. Data on serial weight change were not available from the majority of studies and could not be included in the analysis. In multivariate analysis, only five factors remained as independent prognostic variables-performance status, white blood count, haemoglobin, lactate dehydrogenase and the number of metastatic sites (Table 4). These factors were used for development of a prognostic index as a predictive model for survival (see Discussion).

\section{Analysis of toxicity}

In univariate analyses for grade 3 or 4 toxicity, treatment with CT or non-CT drugs, gender, performance status and baseline creatinine, albumin and age were all significant factors (Table 5). Haematological indices, lactate dehydrogenase, dose level and disease stage were not significant. In multivariate analysis, the class of drug, elevated platelet count, low white blood count and 
Table 2 Comparisons between CT and non-CT groups

\begin{tabular}{|c|c|c|c|c|}
\hline Variable & & Non-cytotoxic & Cytotoxic & $P$-value (test) \\
\hline Female & Total 210 & $|3|(42.8 \%)$ & 79 (69.3\%) & $<0.001$ \\
\hline Male & Total 210 & $175(57.2 \%)$ & $35(30.7 \%)$ & $\left(\chi^{2}\right)$ \\
\hline Median age (range) & & $58(22-87)$ & $55(26-76)$ & $0.04(M-W)$ \\
\hline \multicolumn{5}{|l|}{ WHO performance status } \\
\hline 0 & & $143(48.2 \%)$ & $35(31.5 \%)$ & \\
\hline \multicolumn{5}{|l|}{ Number of metastatic sites } \\
\hline $0-1$ & & $142(48.6 \%)$ & $47(41.6 \%)$ & 0.20 \\
\hline$\geqslant 2$ & & $150(51.4 \%)$ & $66(58.4 \%)$ & $\left(\chi^{2}\right)$ \\
\hline \multicolumn{5}{|l|}{ Lung involvement } \\
\hline No & & $221(73.7 \%)$ & $75(65.8 \%)$ & 0.11 \\
\hline Yes & & $79(26.3 \%)$ & $39(34.2 \%)$ & $\left(\chi^{2}\right)$ \\
\hline \multicolumn{5}{|l|}{ Median overall survival (days) } \\
\hline \multicolumn{5}{|l|}{ Liver involvement } \\
\hline No & & 235 & 260 & $0.86(L R)$ \\
\hline Yes & & 137 & 228 & $0.02(\mathrm{LR})$ \\
\hline \multicolumn{5}{|l|}{ Lung involvement } \\
\hline No & & 202 & $27 \mid$ & $0.40(L R)$ \\
\hline Yes & & 162 & 228 & $0.83(\mathrm{LR})$ \\
\hline Median duration of trial (days) & & 51 & 73 & $<0.001(\mathrm{M}-\mathrm{W})$ \\
\hline \multicolumn{5}{|l|}{ Response to treatment: (overall) } \\
\hline CR $(0.3 \%)$ & & 0 & | (0.9\%) & \\
\hline PR (4.6\%) & & $3(1.0 \%)$ & $15(13.2 \%)$ & $<0.001$ \\
\hline $\mathrm{SD}(19.2 \%)$ & & $42(13.7 \%)$ & $36(31.6 \%)$ & excluding NE \\
\hline PD (64.8\%) & & $221(72.2 \%)$ & 55 (48.2\%) & (Fisher's) \\
\hline NE $(11.1 \%)$ & & $40(13.1 \%)$ & $7(6.1 \%)$ & \\
\hline
\end{tabular}

$M-W=$ Mann-Whitney $U$-test; Fisher's = Fisher's exact $t$-test; $L R=$ log-rank test; $\chi^{2}=$ chi-squared test; $C R=$ complete response; PR $=$ partial response; $S D=$ stable disease; $\mathrm{PD}=$ progressive disease; $\mathrm{NE}=$ not evaluable. All responses assessed using standard $\mathrm{WHO}$ criteria.

gender were the only significant independent variables for toxicity (Table 6).

\section{DISCUSSION}

The continued development of new anticancer drugs is dependent upon patient entry into phase I clinical trials. Treating physicians have an ethical and moral responsibility to be sure that they do not compromise patient survival or expose patients to unacceptable toxicity. Equally, while not the primary end point of phase I studies, individual trials have limited statistical powers and potentially beneficial therapies should not be rejected without thorough assessment. This retrospective analysis of 420 patients, treated in 16 phase I studies, is the first to address whether there are differences in outcome for patients entered into CT and nonCT phase I trials. Conventional multivariate analyses were used to elucidate which factors appear to be important for predicting toxicity and survival. The extent to which physician bias may have influenced patient entry into studies has not been determined in the analysis but must be considered. All patients were treated at a single institution, by three physicians, using agreed shared protocols to minimise bias.

Not surprisingly, treatment with a CT drug as opposed to a nonCT agent was an independent variable for predicting grade 3 or 4 toxicity. Traditional phase I design includes dose escalations, by cohort, until significant toxicities are observed. With studies of non-CT agents, conventional criteria for achieving a maximum tolerated dose are not always achieved. This may account for the lack of significance of dose level for predicting grade 3/4 toxicity. Other factors that did predict toxicity included a low white blood count, platelet count above the normal range and female sex. Haematological indices provide nonspecific markers of inflammatory changes and thus may be expected to predict for toxicity. A low white blood count may also reflect extensive prior cytotoxic treatment or an immunocompromised patient. Gender was an unexpected predictor. A report of patients with colorectal cancer found greater 5-fluorouracil (5-FU)-induced toxicity in women (Sloan et al, 2002). In our analysis, data from a phase I study of cyclophosphamide, methotrexate and infusional 5-FU in breast cancer patients was included. However, if this study is excluded the toxicity results remain significant. Female gender is also a significant factor for toxicity in non-CT trials. This may be due to patients with breast or ovarian cancer entering phase I trials after extensive previous cytotoxic chemotherapy and radiotherapy. The large number of trials of different agents, with multiple mechanisms of action, suggest to us that physiological factors are unlikely to account for the increased grade 3/4 toxicity in females although this cannot be ruled out.

One of the aims of this analysis was to determine if there is a difference in outcome between CT and non-CT phase I trials. Direct comparison from data in this analysis has been restricted by 
Table 3 Univariate survival analysis, all patients

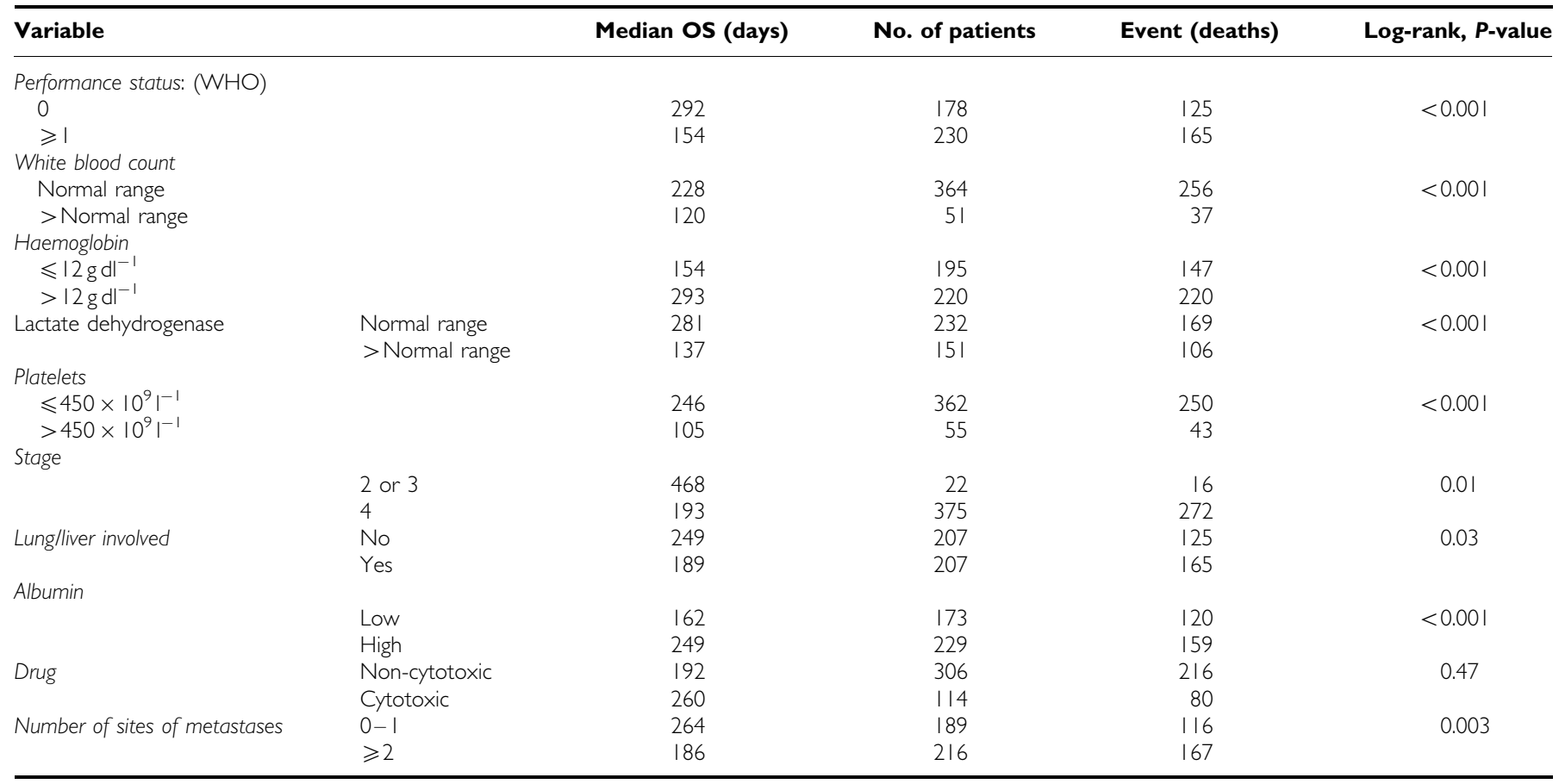

Table 4 Multivariate survival analysis, all patients

\begin{tabular}{|c|c|c|c|}
\hline Variable & Hazard ratio & $95 \% \mathrm{Cl}$ & $P$-value \\
\hline \multicolumn{4}{|c|}{ Performance Status (WHO) } \\
\hline 0 & Baseline & & \\
\hline$\geqslant 1$ & 1.48 & $1.15-1.92$ & 0.003 \\
\hline \multicolumn{4}{|l|}{ White blood count } \\
\hline $\begin{array}{l}\text { normal range } \\
\text { above normal range }\end{array}$ & $\begin{array}{l}\text { Baseline } \\
1.65\end{array}$ & $1.13-2.40$ & 0.01 \\
\hline \multicolumn{4}{|l|}{ Haemoglobin } \\
\hline $\begin{array}{l}>12 \mathrm{gdl}^{-1} \\
\leqslant 12 \mathrm{gdl}^{-1}\end{array}$ & $\begin{array}{l}\text { Baseline } \\
1.60\end{array}$ & $1.23-2.08$ & $<0.001$ \\
\hline \multicolumn{4}{|l|}{ Lactate dehydrogenase } \\
\hline $\begin{array}{l}\text { Normal range } \\
>\text { Normal range }\end{array}$ & $\begin{array}{l}\text { Baseline } \\
1.54\end{array}$ & $1.18-2.01$ & 0.002 \\
\hline \multicolumn{4}{|c|}{ Number of sites of metastases } \\
\hline $0-1$ & Baseline & & \\
\hline$\geqslant 2$ & 1.5 & $1.16-1.93$ & 0.002 \\
\hline
\end{tabular}

the imbalance in number of patients receiving CT $v s$ non-CT trials (114 vs 306 patients respectively). Initial observations on patient demographics found significantly more women and patients with liver metastases received CT drugs while more patients with an initial performance status of zero were entered into studies with non-CT drugs. These differences may indicate that oncologists are selective about which trials are offered to patients. Alternatively, patients considering entry into a phase I trial are selective about which drugs they prefer to receive, based on perceived efficacy or toxicity. A previous study on perceptions of patients entering phase I trials suggested that many were strongly motivated by the hope of therapeutic benefit (Daugherty et al, 1995) and, if offered a choice of studies, may consider this carefully.

Tumour response and survival were secondary end points in every phase I trial conducted. In this study, more patients obtained an objective tumour response and disease stabilisation when treated with a CT drug compared to a non-CT drug (14.1\% vs $1.0 \%$
Table 5 Univariate analysis for $\mathrm{WHO}$ grade 3/4 toxicity, all patients

\begin{tabular}{|c|c|c|c|c|}
\hline Variable & $\begin{array}{l}\text { Odds } \\
\text { ratio }\end{array}$ & $\begin{array}{c}\text { Toxicity } \\
\text { grade }<3\end{array}$ & $\begin{array}{c}\text { Toxicity } \\
\text { grade } 3 / 4\end{array}$ & $P$-value \\
\hline \multicolumn{5}{|l|}{ Treatment } \\
\hline Non-cytotoxic drugs & Baseline & 191 & 107 & \multirow[t]{2}{*}{$<0.00$ I } \\
\hline Cytotoxic drugs & 2.95 & 43 & 71 & \\
\hline \multicolumn{5}{|l|}{ Sex } \\
\hline Female & Baseline & 94 & 111 & \multirow[t]{2}{*}{$<0.00$ I } \\
\hline Male & 0.41 & 140 & 67 & \\
\hline \multicolumn{5}{|l|}{ Performance status (WHO) } \\
\hline 0 & Baseline & 114 & 64 & \multirow[t]{2}{*}{0.01} \\
\hline$\geqslant 1$ & 1.69 & 115 & 109 & \\
\hline \multicolumn{5}{|l|}{ Creatinine (range) } \\
\hline Lower & Baseline & 64 & 74 & \multirow{3}{*}{0.006} \\
\hline Middle & 0.62 & 81 & 58 & \\
\hline Upper & 0.46 & 87 & 46 & \\
\hline \multicolumn{5}{|l|}{ Age (Years) } \\
\hline$<65$ & Baseline & 163 & $14 \mid$ & \multirow[t]{2}{*}{0.03} \\
\hline$\geqslant 65$ & 0.6 & 71 & 37 & \\
\hline \multicolumn{5}{|l|}{ Albumin } \\
\hline Normal range & Baseline & 87 & 83 & \multirow[t]{2}{*}{0.03} \\
\hline$>$ Normal range & 0.63 & $14 \mid$ & 85 & \\
\hline
\end{tabular}

and $31.6 \%$ vs $13.7 \%$, respectively). The high response rates seen with CT drugs reflects the inclusion of two phase I trials of novel schedules of drugs known to have significant antitumour activity (i.e. cyclophosphamide, methotrexate and infusional 5-FU; 5-FU, folinic acid and interferon). Subanalysis of response rates in the phase I studies of novel CT drugs, excluding these two trials, still showed a partial response rate of $10.3 \%$, which is higher than many previous reports (Estey et al, 1986; Decoster et al, 1990; Bachelot et al, 2000; Sekine et al, 2002). Several of these drugs were new selective topoisomerase inhibitors and would be predicted to have antitumour activity. Tumour type was not a significant predictor of outcome in this analysis, although numbers of patients with each cancer site were small. It is not clear why patients in phase I 
Table 6 Multivariate analysis for WHO toxicity grade 3/4

\begin{tabular}{llll}
\hline Variable & Hazard ratio & $\mathbf{9 5 \%} \mathbf{C l}$ & P-value \\
\hline $\begin{array}{l}\text { Drug } \\
\text { Non-cytotoxic }\end{array}$ & Baseline & & \\
$\quad$ Cytotoxic & 2.65 & $1.66-4.24$ & $<0.001$ \\
$\begin{array}{l}\text { Platelet } \\
\quad \leqslant 450 \times 10^{9} 1^{-1}\end{array}$ & Baseline & & \\
$\quad>450 \times 10^{9} 1^{-1}$ & 2.17 & $1.14-4.13$ & 0.02 \\
Sex & & & \\
$\quad$ Female & Baseline & & \\
$\quad$ Male & 0.48 & $0.31-0.73$ & $<0.001$ \\
White blood count & & & \\
Low & Baseline & & \\
Middle & 0.66 & $0.40-1.10$ & 0.11 \\
High & 0.52 & $0.31-0.89$ & 0.02 \\
\hline
\end{tabular}

studies of CT drugs remained on trial medication for significantly longer (73 vs 51 days). Disease progression was the usual reason for discontinuing treatment. Disease response and stabilisation favoured patients receiving CT rather than non-CT drugs. It is possible that patients treated with cytotoxic agents stayed on study longer because they responded or had stable disease. While higher response rates were seen with CT drugs, there was no statistically significant difference in patient survival between the classes of drugs (260 vs 192 days, $P=0.47)$. This finding should be interpreted with caution. More patients with a performance status of zero entered studies with non-CT drugs $(48.2 \%$ of patients $v s$ $31.5 \%$ of patients in CT trials, $P=0.02$ ) and survival may, therefore, reflect the natural history of the cancer rather than an effect of treatment. However, when groups were matched for performance status there was still no significant difference $(P=0.45)$, although numbers of patients were small. Analysis of patients with liver metastases found that those treated with a non-CT drug had poorer survival compared to those treated with a CT drug (137 vs 228 days, $P<0.02)$. This may be of importance when considering the choice of phase I study although must be considered with caution, as only 127 patients were included with liver metastases. The extent of liver disease was not known.

No comparable data set exists for survival of patients who elected not to enter phase I trials. Thus, assessment of how entry into phase I trials affects survival in this patient population cannot be made. It would seem unlikely, based on the toxicity data, that participation in a phase I clinical trial compromised survival. The impact on quality of life is not known.

Establishing independent prognostic indices for survival of patients treated in phase 1 studies makes it possible to develop a predictive model for the likely survival of individual patients. The five factors we identified in this analysis were: performance status (zero vs one or greater), white blood count (normal range $v s$ above normal range), haemoglobin (less than or equal to $12 \mathrm{~g} \mathrm{dl}^{-1}$ vs greater than $12 \mathrm{~g} \mathrm{dl}^{-1}$ ), lactate dehydrogenase (normal range $v s$ above normal range) and number of sites of metastases (zero or one $v s$ two or more sites). These risk factors can be used to identify whether patients have a good, intermediate or poor risk of survival (Table 7, Figure 1). Independent analysis shows a significant difference between each group for survival, ranging from a median of 321 days for the good risk group to 117 days for the poor risk group. Prognostic factors for individual patients can be entered into this model and median survival estimated.

Of the 16 phase I studies included in uni- and multivariable analyses, two studies employed 'standard' chemotherapy administered in a novel schedule or in combination with biological modulators. These potentially more effective treatments might
Table 7 Prognostic model for prediction of survival

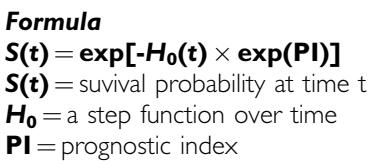

\begin{tabular}{lcccc}
\hline Group & $\begin{array}{c}\text { Risk factors } \\
(\boldsymbol{n})\end{array}$ & $\begin{array}{c}\text { Patients } \\
(\boldsymbol{n})\end{array}$ & $\begin{array}{c}\text { Events } \\
(\boldsymbol{n})\end{array}$ & $\begin{array}{c}\text { Median } \\
\text { survival } \\
\text { (days) }\end{array}$ \\
\hline Good risk & $0-1$ & 136 & 91 & 321 \\
Intermediate risk & 2 & 96 & 64 & 257 \\
Poor risk & $\geqslant 3$ & 127 & 105 & 117 \\
\hline
\end{tabular}

Log-rank test:

$\begin{array}{ll}\text { Overall: } & P<0.00 \text { I } \\ \text { Good vs Intermediate } & P=0.004 \\ \text { Intermediate vs poor } & P<0.00 \text { I } \\ \text { Good vs poor } & P<0.001\end{array}$

Patients were divided into three groups depending upon the number of adverse risk factors (i.e performance status $>$ I, white blood count $>$ normal range, haemoglobin $<12 \mathrm{~g} \mathrm{dl}^{-1}$, lactate dehydrogenase above normal range, number of sites of metastases $>2$ ). Each risk factor counts as 1 .

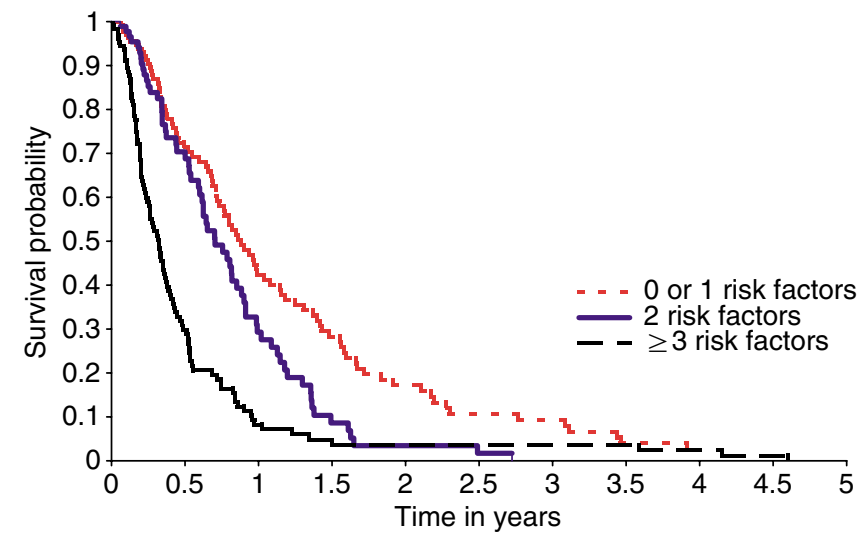

Figure I Predicted survival for patients entered into phase I clinical trials using independent prognostic indices identified from multivariate analysis (performance status, white blood count, haemoglobin, lactate dehydrogenase and number metastastic sites). Patients are categorised into good $(0$ or I risk factors), intermediate (2 risk factors) or poor risk ( $\geqslant 3$ risk factors).

therefore have biased the results of this study. Exclusion of these two studies, from the comparisons of CT and non-CT phase I trials, univariables and multivariable analyses did not significantly affect the statistical results.

The development of prognostic indices for toxicity and survival are important considerations in the design of early phase clinical trials. This retrospective analysis is the first to be reported, that directly considers phase I non-CT trials. Differences were identified in baseline characteristics of patients entered into nonCT phase I studies compared to CT trials. It is not clear whether this is due to physician bias or patient choice. Most importantly, no significant difference in median overall survival was found between the two treatment groups. The use of prognostic models, as proposed from this analysis, may be important for discussing patient entry into trials and could, in future, be helpful as part of the inclusion criteria. The model developed in this study uses five independent factors and further work, with other large data sets from phase 1 trial centres, is required for validation and determination of its use prospectively. 


\section{ACKNOWLEDGEMENTS}

This work was funded by Cancer Research UK. The authors acknowledge all the patients who have participated in the phase I trials described in this paper. We are grateful to Kay Castle for secretarial support.

\section{REFERENCES}

American Society of Clinical Oncology (1997) Critical role of phase I clinical trials in cancer treatment. J Clin Oncol 15: $853-859$

Bachelot T, Ray-Coquard I, Catimel G, Ardiet C, Guastalla JP, Dumortier A, Chauvin F, Droz JP, Philip T, Clavel M (2000) Multivariable analysis of prognostic factors for toxicity and survival for patients enrolled in phase I clinical trials. Ann Oncol 11: $151-156$

Braybrooke JP, Boven E, Bates NP, Ruijter R, Dobbs N, Cheverton PD, Pinedo HM, Talbot DC (2003) Phase I and pharmacokinetic study of the topoisomerase I inhibitor, exatecan mesylate (DX-8951f) using a weekly 30-minute intra-venous infusion, in patients with advanced solid malignancies. Ann Oncol 14: $913-921$

Braybrooke JP, Propper DJ, O’Byrne KJ, Koukourakis MI, Patterson AV, Houlbrook S, Love SD, Varcoe S, Taylor M, Ganesan TS, Talbot DC, Harris (2000) Induction of thymidine phosphorylase as a pharmacodynamic end-point in patients with advanced carcinoma treated with 5-fluorouracil, folinic acid and interferon alpha. $\mathrm{Br} J$ Cancer 83: 219-224

Chao D, Bahl P, Smith C, Dunbar R, Cerundolo V, Thurner-Schuler B, Austyn JM, Harris AL (2003) A phase I clinical trial of direct intratumoral injection of autologous dendritic cells. $\mathrm{Br} J$ Cancer, submitted

Daugherty C, Ratain MJ, Grochowski E, Stocking C, Kodish E, Mick R, Siegler M (1995) Perceptions of cancer patients and their physicians involved in phase I trials. I Clin Oncol 13: $1062-1072$

Decoster G, Stein G, Holdener EE (1990) Responses and toxic deaths in phase I clinical trials. Ann Oncol 1: 175-181

Estey E, Hoth D, Simon R, Marsoni S, Leyland-Jones B, Wittes R (1986) Therapeutic response in phase I trials of antineoplastic agents. Cancer Treat Rep 70: $1105-1115$

Green S, Weiss G (1992) Southwest Oncology Group standard response criteria, endpoint definitions and toxicity criteria. Investigational New Drugs. Ann Oncol 10: 239-253

Janisch L, Mick R, Schilsky RL, Vogelzang NJ, O’Brien S, Kut M, Ratain MJ (1994) Prognostic factors for survival in patients treated in phase I clinical trials. Cancer 74: $1965-1973$

Jones P, Elliot M, Dobbs N, Kakkar A, Talbot DC, Ganesan TS, Harris AL (1999) Phase I/II study of combination antiangiogenesis therapy with marimastat, captopril and fragmin. Proc Am Soc Clin Onc 18: $447 \mathrm{a}$

Jones PH, Burnett RD, Fainaru I, Nadolny P, Tang-Liu D, Walker P, Yu Z, Ganesan TS, Talbot DC, Harris AL, Rustin GJS (2003) A phase I study of tazarotene in adults with advanced cancer. Br J Cancer, submitted

Levit NC, Eskens FA, O’Byrne KJ, Propper DJ, Denis LJ, Owen SJ, Choi L, Foekens JA, Wilner S, Wood JM, Nakajima M, Talbot DC, Steward WP, Harris AL, Verweij J (2001) Phase I and pharmacological study of the oral matrix metalloproteinase inhibitor, MM1270 (CGS27023A), in patients with advanced solid cancer. Clin Cancer Res 7: 1912-1922

Macaulay VM, O’Byrne KJ, Saunders MP, Braybrooke JP, Long L, Gleeson F, Mason CS, Harris AL, Brown P, Talbot DC (1999) Phase I study of intrapleural batimastat (BB-94), a matrix metalloproteinase inhibitor, in the treatment of malignant pleural effusions. Clin Cancer Res 7: 513-520

Miller AB, Hoogstraten B, Staquet M, Winkler A (1981) Reporting results of cancer treatment. Cancer 47: $207-214$

National Cancer Institute Guidelines: for the Reporting of Adverse Drug Reactions (1988) Division of Cancer Treatment, National Cancer Institute, Bethesda, MD

O’Byrne KJ, Koukourakis MI, Saunders MP, Salisbury AJ, Isaacs R, Varcoe S, Taylor M, Ganesan TS, Harris AL, Talbot DC (1998) Cyclophosphamide, methotrexate and infusional 5-fluorouracil (infusional CMF) in metastatic breast cancer. Br J Cancer 77: 1950-1956

Philip PA, Rea D, Thavasu P, Carmichael J, Stuart NS, Rockett H, Talbot DC, Ganesan T, Pettit GR, Balkwill F et al (1993) Phase I Study of bryostatin 1: assessment of interleukin 6 and tumor necrosis factor alpha induction in vivo. Cancer Inst 85: 1812-1818

Propper DJ, de Bono J, Saleem A, Ellard S, Flanagan E, Paul J, Ganesan TS, Talbot DC, Aboagye EO, Price P, Harris AL, Twelves C (2003) Use of positron tomography in pharmacokinetic studies to investigate therapeutic advantage in a phase I study of 120-hour intravenous infusion XR5000. J Clin Oncol 21: 203-210

Propper DJ, Saunders MP, Salisbury AJ, Long L, O’Byrne KJ, Braybrooke JP, Dowsett M, Taylor M, Talbot D C, Ganesan TS, Harris AL (1999) Phase I study of the novel cyclic AMP (cAMP) analogue 8-chloro-cAMP in patients with cancer: toxicity, hormonal and immunological effects. Clin Cancer Res 5: $1682-1689$

Sekine I, Yamarnoto N, Kunitoh H, Ohe Y, Tamura T, Kodarna T, Saijo N (2002) Relationship between objective responses in phase I trials and potential efficacy of non-specific cytotoxic investigational new drugs. Ann Oncol 13: $1300-1306$

Sloan JA, Goldberg RM, Sargent DJ, Vargas-Chanes D, Nair S, Cha SS, Novotny PJ, Poon MA, O'Connell MJ, Loprinzi CL (2002) Women experience greater toxicity with fluorouracil-based chemotherapy for colorectal cancer. J Clin Oncol 20: $1491-1498$

Twelves C, White J, Carmichael J, Harris A, Verrill J, Carmichael J, Farebrother J, Smith R, Misra N, Laight A (2002) A phase I pharmacokinetic and tolerability trial of ZD1839 (Iressa) in hepatically impaired patients with solid tumours. Proc Am Soc Clin Oncol, 21: 85 a

Von Hoff DD, Turner J (1991) Response rates, duration of response, and dose response effects in phase I studies of antineoplastics. Invest New Drugs 9: $115-122$ 